Behaviour of Metals at Elevated Temperatures Lectures delivered at the Institution of Metallurgists Refresher Course, 1956. Pp. vii $+122+3$ plates. (London: Iliffe and Sons, Ltd. ; New York: Philosophical Library, 1957. Published for the Institution of Metallurgists.) 21s, net.

THE ever-increasing temperatures for which engineers design and at which they operate their plant has made heavy demands on the metallurgist. The stability of alloys during long-continued stressing at elevated temperatures has been improved to an extent which is highly creditable to those through whose research and development work these new materials have been produced, but it is still true that changes in materials under stress at high temperatures are one of the main factors which retard engineering development in a wide range of fields. The book under review contains four lectures given to the Institution of Metallurgists in 1956 in which the present position is excellently surveyed and in which the main lines of future development are laid down. These lectures contain little which is absolutely new, but they all, in their own ways, represent most able critical reviews of the existing state of knowledge, admirably condensed and expressed in terms of immediate practical value.

These papers include one by Dr. N. P. Allen, of the National Physical Laboratory, on "The Engineering Properties of Metals at High Temperatures", which gives a general picture of the whole field which could scarcely be bettered. The other three deal with more specific sections : one on "The Effect of Temperatures up to $450^{\circ}$ C. on Metals", by G. Meikle, of the Royal Aireraft Establishment, Farnborough; the second, by Dr. L. B. Pfeil, of the Mond Nickel Co., Ltd., on "Non-Ferrous High-Temperature Materials", which deals in large measure, though not entirely, with the outstanding range of high-temperature nickel and cobalt alloys, in the development of which Dr. Pfeil himself has played so significant a part ; and finally, a paper on "High-Temperature Steels", by W. E. Bardgett, research manager of the United Steel Companies, Ltd. All these are well presented and illustrated, and the book as a whole represents a most useful contribution to the subject.

\section{F. C. Thompson}

Space Research and Exploration

Edited by Prof. D. R. Bates, in association with Patrick Moore. Pp. 224. (London: Eyre and Spottiswoode (Publishers), Ltd., 1957.) 25s. net.

7 HE great upsurge of interest in artificial satellites and space-flight during the past few years has opened the way for a flood of publications on the subject, not all of high scientific merit. The present book strikes a reasonable balance between the uninformed enthusiasm of the space-travel addicts and the sober scientific facts and problems in our limited knowledge of conditions on the fringe of the Earth's atmosphere and in interplanetary space. This book lays emphasis on the underlying principles of rocket propulsion and orbital mathematics and gives a useful appraisal of the possibilities of escape from the Earth's gravitational field and travel to other planets, with only a minimum of the customary optimistic speculation on more ambitious space voyages. A number of individual contributions have been brought together by the editors, covering all aspects of the subject, from basic rocket principles and performance, to the propertios and likely biological effects of cosmic rays on would-be space-men. Inevitably, there is a good deal of overlap and variation in treatment, but the general aim of presenting a comprehensive and intelligible survey of the subject to the intelligent public is achieved. A few details of metoor statistics and orbital mathematies are given in appendixes; several minor errors occur, especially in Appendix 9. The most interesting part of the book is devoted to a summary of our present knowledge of the basic physical properties of the upper atmosphere, solar radiation, auroras, magnetic storms and ionospheric characteristics. The gaps in current knowledge and the exciting hopes of filling them by observations from satellites and research rockets are lucidly discussed in chapters by Prof. H. S. W. Massey, chairman of the British Grssiot Committee (which is responsible for scientific co-ordination of the British upper-atmosphere rocket-research programme). Due credit is given to the important results already gained from rocket measurements, although the superiority of artificial satellites as means of long-duration observation is recognized.

\section{Miscelanea Geofisica publicada pelo Servico Meteor- ologico de Angola em Commemoracao do $X$ Aniversario do Servico Meteorologico Nacional} Pp. $v+366$. (Luanda : Servico Meteorologico de Angola, 1956.) n.p.

THIS volume is a 'Festachrift' published on the occasion of the tenth anniversary of the national meteorological service of Portugal and Portuguese overseas territories and it is dedicated to the director, Dr. Amorim Ferreira.

It contains twenty-seven papers contributed from twelve different countries, including two by Portuguese authors. About half the papers are on the meteorology of central Africa but the others are on a wide variety of topics having no direct relevance to the meteorology of Angola. The two papers on Angola itself are both by German authors; K. Keil gives a bibliography of early meteorological observations in the territory and $\mathrm{H}$. Flohn studies the oquatorial west winds of Angola-two solid, informative papers. There are several papers on the climatology of the adjoining Belgian Congo. The other papers cover a very wide range, from oceanographic instruments devised in Japan to the precipitation of the Canadian prairies. J. Chase (Woods Hole) gives an interesting account with synoptic charts of the occasions when deep depressions have been near the Azores instead of the usual anticyclone. Dr. De Jong (Holland) discusses the construction and use of the composite charts drawn for aviation forecasting which show the isobars and fronts as they are expected to be when an aeroplane flying on a specific route reaches the corresponding area, and R. F. Murgatroyd describes the work of the British Meteorological Research Flight. There are mathematical papers by P. Defrise and others (Belgium) on the harmonic analysis of the height, kinetic energy and meridional flux of sensible heat on the $500-\mathrm{mb}$. surface at latitude $50^{\circ}$ N., and by J. P. Peixoto (Lisbon) on Fourier spectral analysis in geophysical problems.

One cannot help feeling that it would have been preferable for some of the contributions not specifically related to Central Africa to have been published in the usual journals and not in a book of this kind where they will tend to be lost, and to have published in this volume only papers on the meteorology of Angole and the surrounding parts of Africa. G. A. BULL 